\title{
Vesicovaginal Fistula Post Caesarean Hysterectomy
}

\author{
Manisha Maharjan, Aruna Karki, Ganesh Dangal, Hema Pradhan, Ranjana Shrestha, Rekha Poudel, Nishma
} Bajracharya, Shreena Shrestha, Kenusha Devi Tiwari, Sonu Bharati

Department of Obstetrics and Gynecology, Kathmandu Model Hospital, Nepal

Received: November 12, 2019

Accepted: March 15, 2020

\begin{abstract}
Genitourinary fistula is an abnormal communication between the urinary tract and genital tract, most common being the vesicovaginal fistula. In most of the cases fistula results mainly due to poor obstetric care in developing countries, where as in developed countries most of the urogenital fistulas are iatrogenic. It is mainly diagnosed by clinical examinations and intravesical dye test using methylene blue. Repair can be done via abdominal or vaginal route based on the findings. Here we present a case of 27 years postnatal mother referred to our centre with diagnosis of vesicovaginal fistula post cesarean hysterectomy that was repaired successfully via vaginal approach.
\end{abstract}

Keywords: cesaerean hysterectomy, urinary leakage, vesicovaginal fistula

Citation : Maharjan M, Karki A, Dangal G, Pradhan H, Shrestha R, Poudel R, et al. Vesicovaginal Fistula Post Caesarean Hysterectomy. Nep J Obstet Gynecol. 2020;15(30):84-85. DOI: 10.3126/njog.v15i1.29351

\section{INTRODUCTION}

Vesicovaginal fistula (VVF) is an abnormal communication between the urinary bladder and the vagina resulting in an involuntary leakage of urine from vagina. ${ }^{1}$ Lahore. Study Design: An observational study. Place and Duration of Study: Lady Willingdon Hospital, Lahore, from January 2007 to December 2008. InMethodology: All cases of VVF treated at the centre during the study period were included in the study. The patients were admitted and evaluated through detailed history, physical examination, relevant investigations and evaluation under general anaesthesia (EUA Fistulas are a recurring problem in areas where women have inadequate access to quality emergency obstetric care in developing countries, affecting patient's medical, physical, mental, social and sexual life. ${ }^{2}$ It is estimated that more than 2 million young women live with untreated obstetric fistula in Asia and sub-Saharan Africa. Iatrogenic postoperative VVF is the most common in developed countries, compared to mainly obstetric trauma in developing countries. ${ }^{3}$

The physical and psychological impact of constant urinary incontinence from VVF can be overwhelming

\section{CORRESPONDENCE}

Dr. Manisha Maharjan

Paropakar maternity and Women Hospital, Kathmandu, Nepal

Email: manishamaharjan672@gmail.com:

Mobile: $+977-9808556088$ because of the burden of continual wetness, undesirable odors, vaginal and bladder infections and associated discomfort. The success rate has been associated with etiology of fistula, site of fistula, size of the fistula and number of previous failed attempts at repair. ${ }^{4}$

\section{CASE}

A 27 years postnatal woman referred-in to our center for VVF repair with history of continuous leakage of urine since her $20^{\text {th }}$ postpartum day following caesarean hysterectomy who didn't respond on indwelling catheter for three weeks. She had undergone emergency caesarean section 6 months ago for placenta previa with previous LSCS and had caesarean hysterectomy for intractable PPH. Diagnosis was reconfirmed by per speculum and methylene blue dye test, and abdominal ultrasound was normal.

Under subarachnoid block, she was evaluated, a fistulous opening around $2 * 2 \mathrm{~cm}$ was noted at vault. Wide dissection of fistulous margin was done, followed by mobilization of urinary bladder, margins freshened and edges approximated in layers with vicryl 2-0 suture. Dye test repeated following 
the repair, was negative. Then, the edges were restrengthened in additional layer followed by closure of the vault. Vaginal pack was placed for 24 hours. Catheratisation was done with 16 F Foley's catheter for three weeks. She was kept on antibiotic coverage for one week. During the hospital stay, she drank adequately, with adequate urine output, and was dry and incontinent. Dye test repeated on day 21 of VVF repair, was negative and hence catheter was removed. She was discharged continent and dry. At one week follow up she had no complains.

\section{COMMENTS}

The etiology of VVF is varied worldwide, with obstructed prolonged labour being the most common cause accounting for more than $90 \%$ of VVF cases in developing countries. Iatrogenic bladder injury during pelvic surgery, most commonly hysterectomy, accounts for more than two thirds of cases in well developed countries. ${ }^{6}$ The acute onset of urinary incontinence occurring shortly after a difficult hysterectomy should raise suspicions for vesicovaginal or ureterovaginal fistulas. ${ }^{5}$

During lower segment cesarean section, the bladder base may be injured, causing ischemia or included in a suture to result in a fistula which usually communicates to the uterus or cervix. During delivery of large fetal head, there might be trauma to the bladder if there is no adequate mobilization of bladder laterally and inferiorly. With increase in the incidence of cesarean section, the risk of bladder injury has also increased, with the risk being doubled in repeat cesarean section. ${ }^{7}$ During abdominal hysterectomy the commonest site of VVF is at the vaginal vault in the posterior bladder wall, this being the usual site of bladder injury. ${ }^{8}$ This is the situation in the present study as well.

If VVF is diagnosed within the first few days of surgery, a transurethral or suprapubic catheter should be placed and maintained for up to 30 days. The fundamental treatment principles for VVF repair (adequate exposure, tension-free approximation of the fistula edges, non-overlapping suture lines, good homeostasis, watertight closure and adequate postoperative bladder drainage) can be achieved through both, vaginal and abdominal route, depending upon the surgical experience. ${ }^{4}$ The first repair has the highest success rate in VVF, and the best approach is probably the one in which the surgeon is most experienced. Surgical approach is the most commonly preferred for affected women and the success rate varies between $75 \%-95 \%$ in literature. ${ }^{2}$ The success rate has been associated with the etiology of the fistula, site of the fistula, size of the fistula and number of previous failed attempts at repair. ${ }^{4}$

\section{CONCLUSIONS}

Vesicovaginal fistulas are among the most distressing complications of obstetric and gynecologic procedures. Most iatrogenic vesicovaginal fistula result from bladder injury during gynecological or obstetrical procedures. Intraoperative recognition and repair of bladder injury decreases the incidence of VVF formation.

\section{REFERENCES}

1. Raashid Y, Majeed T, Majeed N, Shahzad N, Tayyab S, Jaffri H. Iatrogenic Vesicovaginal Fistula. J Coll Physicians Surg Pak. 2010;20(7):436-8

2. Shrestha R, Karki A, Dangal G, Pradhan H, Bhattachan K, Poudel R, et al. Profile of Obstetric and Iatrogenic Fistula Surgeries at Kathmandu Model Hospital. Nepal J Obstet Gynaecol. 2018;13(2):19-22.

3. Miller S, Lester F, Webster M, Cowan B. Obstetric fistula: a preventable tragedy. J Midwifery Womens Health. 2005;50(4):286-94.

4. Jadav RR, B. MG. An outcome of the management of vesicovaginal fistula: experience at KIMS, Hubli, Karnataka, India. IntSurg J. 2019;6(2):552

5. Mallik AU, Rahman MM, Ferdous B. Vesico Vaginal
Fistula: A Case Report and Review of Literature. KYAMC J. 2018;9(3):136-8.

6. Al-Hammouri F, Alkaabneh AB, Qamar AAA, Naemat AS, Almajali AS, Zraigat AS, et al. Iatrogenic vesicovaginal fistula repair-experience at Prince Hussein Urology and Organ Transplant Center. Int J Res Med Sci. 2019;7(3):765-9.

7. Poudel R, Dangal G, Karki A, Pradhan H, Shrestha R,Bhattachan K et al. Vesicovaginal Fistula Post Emergency Repeat Caesarean Delivery. Nepal J Obstet Gynaecol. 2018;13(2):56-7.

8. Akter S, Mujib F, Rahman MM, Banu DS, Begum T, Firdousi T, et al. Surgical Outcome of Vesico-Vaginal Fistula (VVF) after Repair: Experience of 51 Cases in a Teaching Hospital of Dhaka City. J Natl Inst Neurosci Bangladesh. 2019;5(1):29_ 32 . 